\title{
Funding Science with Science: Cryptocurrency and Independent Academic Research Funding
}

\author{
Edward Lehner, ${ }^{* \dagger}$ Dylan Hunzeker, ${ }^{\ddagger}$ John R. Ziegler ${ }^{\S}$
}

\begin{abstract}
Scientific funding within the academy is an often complicated affair involving disparate and competing interests. Private universities, for instance, are vastly outpacing public institutions in garnering large, prestigious, science-related grants and external research investment. Inequities also extend to the types of research funded, with government, corporate, and even military interests privileging certain types of inquiry. This article proposes an innovative type of science research fund using cryptocurrencies, a fastgrowing asset class. Although not a total funding solution, staking coins, specifically, can be strategically invested in to yield compound interest. These coins use masternode technologies to collateralize the network and speed transaction pace and may pay dividends to masternode holders, allowing institutions that purchase these types of central hubs to potentially engage in a lucrative form of dividend reinvestment. Using cryptocurrencies as a new funding stream may garner large amounts of capital and creation of nonprofit institutes to support the future of funding scientific research within educational institutions.
\end{abstract}

\section{Introduction}

Cryptocurrencies are purely digital assets, backed by the complexity of cryptography and the distributed hashing power used to solve individual blocks on the open ledger. Due to the computing power required to hash transactions, cryptocurrencies cannot be forged or otherwise duplicated. This immutability ascribes to cryptocurrencies an important inherent value, since it can be used to buy goods and services without concern for the funds being duplicated or stolen, provided that security features are employed. Additionally, cryptocurrencies are increasingly becoming a store of value akin to gold as an asset class. This research demonstrates how cryptocurrencies' wealth-generation potential can change the dynamics of institutional funding for science and, more broadly, national funding trends for science, partly shifting the emphasis from grants to a new form of scientific funding.

Geared toward the ultimate goal of funding science research, this article outlines an innovative approach to an actively managed cryptocurrency fund that was assembled by a

\footnotetext{
${ }^{\dagger}$ E. Lehner (edward.lehner@bcc.cuny.edu) is Assistant Professor of Education at Bronx Community College, City University of NY.

${ }^{\ddagger}$ D. Hunzeker (doh2103@columbia.edu) is a researcher and programmer within the blockchain space.

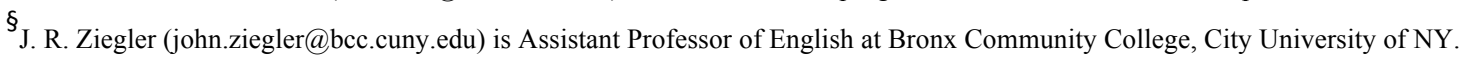


group of academics and bankers who used U.S. dollars (USD) to purchase enough of the selected coins to set up the initial masternodes. The pooled cryptocurrency was strategically deployed to earn lucrative dividends, an active investment strategy using primarily opensource tools, such as Unix, PuTTy, and Linux's Ubuntu. The fund enacts its strategy based on research focusing on cryptocurrency valuation, combining traditional valuation models with predictive equations. Over a six-month period, the fund produced exponential returns over traditional asset classes, yielding well above $400 \%$.

From a broad, less technical perspective, our strategy aligns with Reiss's notion of dividend reinvestment. ${ }^{1}$ Reiss underscored that wealth generation could be achieved by investing in assets and reinvesting any dividends into the original strategy. This notion greatly informed the coin selection that later populated our portfolio. We specifically purchased coins that use the proof-of-stake $(\mathrm{PoS})$ algorithm. Once the initial coin valuation was developed, we populated the portfolio only with coins that returned high-yield dividends. Using the opensource tools mentioned above, the fund's returns were generated by hosting network full nodes, thus receiving a portion of the block reward (the coins generated and paid to PoS holders).

The next step would be to construct a mechanism for distribution of funding that can be overseen and controlled by the researchers themselves. The distribution of funds is relatively straightforward for the prototype fund. However, when others replicate this strategy, a number of decisions will need to be made. For example, once a new fund is operational, funds that are not reinvested can be allocated on a predetermined schedule according to, for instance, faculty/researcher votes on proposals. A minimum disbursement to all researchers at the institutions might also be considered, in order to maintain a foundation of egalitarianism.

\section{How It Works: Diversification and Investment Model Methodology}

Financial diversification is a foundational concept in modern portfolio theory and a timetested way to mitigate against financial exposure to just one asset. This proposal does not call for cryptocurrency to replace all traditional ways to fund science. Rather, it points to the need for financial diversity, held across a number of asset classes, to increase the independence and local control of scientific funding. For instance, Chambers reported that university endowments are a $\$ 100$ billion-dollar industry, yet they often employ traditional strategies derived from managed funds. ${ }^{2}$ In the aftermath of 2008, most endowments lost a significant portion of principal precisely because the strategies were derived from industry standards. While the focus of this article is not endowments, endowment funds may most closely resemble a managed cryptocurrency fund, with the exception that its strategies do not reflect those typical of Wall Street indexes.

It may seem paradoxical to relate traditional finance to the funding of science, yet both fields can become overly reliant on relatively few streams of revenue. Even Miguel Cervantes's Don Quixote cautioned against venturing too many eggs in one basket, but both finance and science have depended, at times, on only a few sources of income. To avoid such over-dependence, investors have long envisioned a different type of financial diversification that did not rely solely upon fiat currency for financial stability. Dating back to the early 1970s, prior to the creation of index funds, Burton G. Malkiel highlighted the need for portfolio diversification. ${ }^{3}$ By the beginning of 1976, Vanguard founded the first index fund, albeit in fiat currency, providing the type of diversification that Malkiel articulated. However, 
in funding science, universities are still largely beholden to government grants and private foundations to support research, a situation that managed cryptocurrency funds can help to rectify.

\section{Cryptocurrency: A New Asset Class}

The white paper that launched Bitcoin, which coincidentally was released at the height of the largest financial crisis in five generations, constituted not only a watershed development for digital currency but also an opportunity to introduce a more secure type of financial diversification against fiat currency in a fully connected world economy. Ultimately, Bitcoin represented a first attempt at a digital, cryptographic, international diversified currency, which essentially afforded a freely traded international asset.

Bitcoin, in effect, created a new type of asset class that could be leveraged against other asset classes, providing needed financial diversification. Robert Greer contended that assets within a class share some fundamental characteristics, yet can saliently differ from one another in their attributes. ${ }^{4}$ Chris Burniske and Adam White, building on Greer's framework, argued that Bitcoin fulfills the requirements of an asset class. ${ }^{5}$ In particular, Burniske and White noted that Bitcoin is unique in that it is not affected by movements in other asset classes, meaning that, despite volatility within its own asset class, it reduces overall risk as part of a portfolio.

Moving beyond Bitcoin's straightforward proof-of-work (PoW) model, our fund deploys newer cryptocurrency algorithms that have generated richer returns. Predicated on a working prototype funded with staking coins, this project positions the current working model for use by science-focused institutions, including research-intensive universities, or, more broadly, any higher education institution. The innovative deployment of staking coins can become a way to fund scientific research that operates not only outside the traditional banking and investment space but also beyond the parameters of National Science Foundation (NSF) and National Institutes of Health (NIH) funding. Staking cryptocurrencies, such as PIVX, Dash, and a number of others, are fully backed by the complexity of cryptography while simultaneously earning dividends. Even though staking coins are prone to volatile price extremes, a staking coin's dividend features tend to offset price fluctuations. The dividend features of staking coins thus position them as a prudent and potentially lucrative choice for science funding diversification.

Figure 1 (below) details one particular strategy that deploys staking coins to fund science. As demonstrated in the working prototype, the model transitions from a theoretical discussion of funding to both an axiological and ontological investment construct. Specifically, the model envisions how Dash and PIVX, requiring 1,000 coins and 10,000 coins respectively, could function as a way to fund research. The example sketches how central hubs, often called masternodes, could generate capital. Central hubs generate dividends, as seen in the shared pool. Once these dividends reach the threshold to acquire an additional central hub, a new central hub can be created, earning even more dividends. 


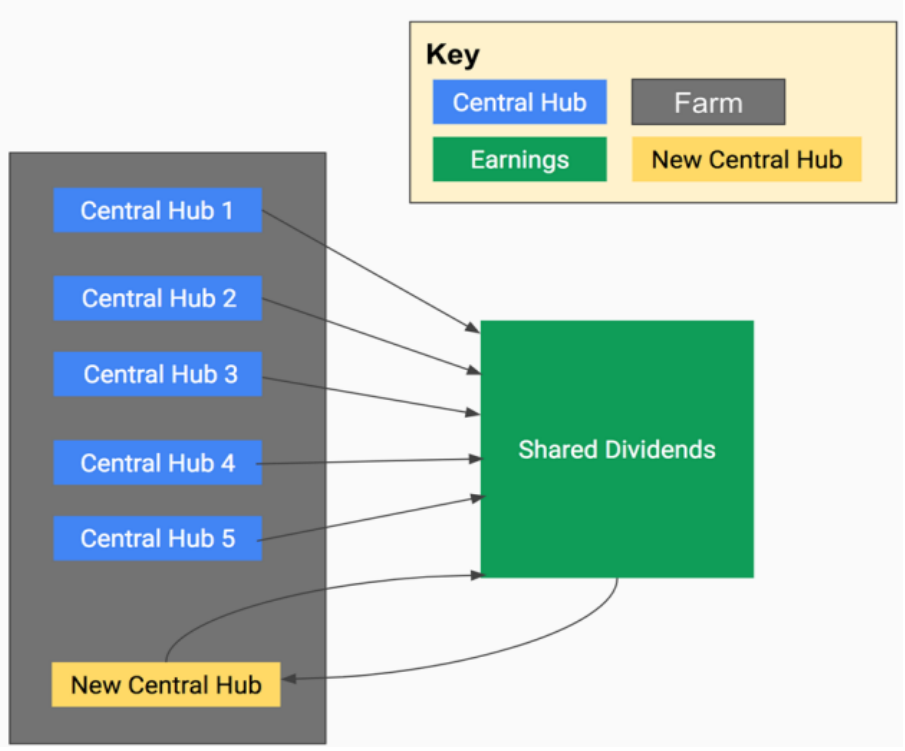

Fig. 1. Model for staking coins for scientific funding. The term masternodes is interchangeable with central hub.

The model in Figure 1 depicts one deployment of staking coins that provides a non-static compound-interest vehicle. Again, this is not a conceptual model: over the past ten months, this group of researchers, in conjunction with software engineers and bankers, has built and used this model, seeing substantial monetary gain. This model holds great promise to augment funding for science, though the prototype needs to be more fully tested and should serve primarily as a portfolio diversifier rather than a total funding solution.

Figure 2 (below) highlights the growth of both Dash (from February 2014 to August 2017) and PIVX (from February 2016 to August 2017).

\section{Dash Charts}
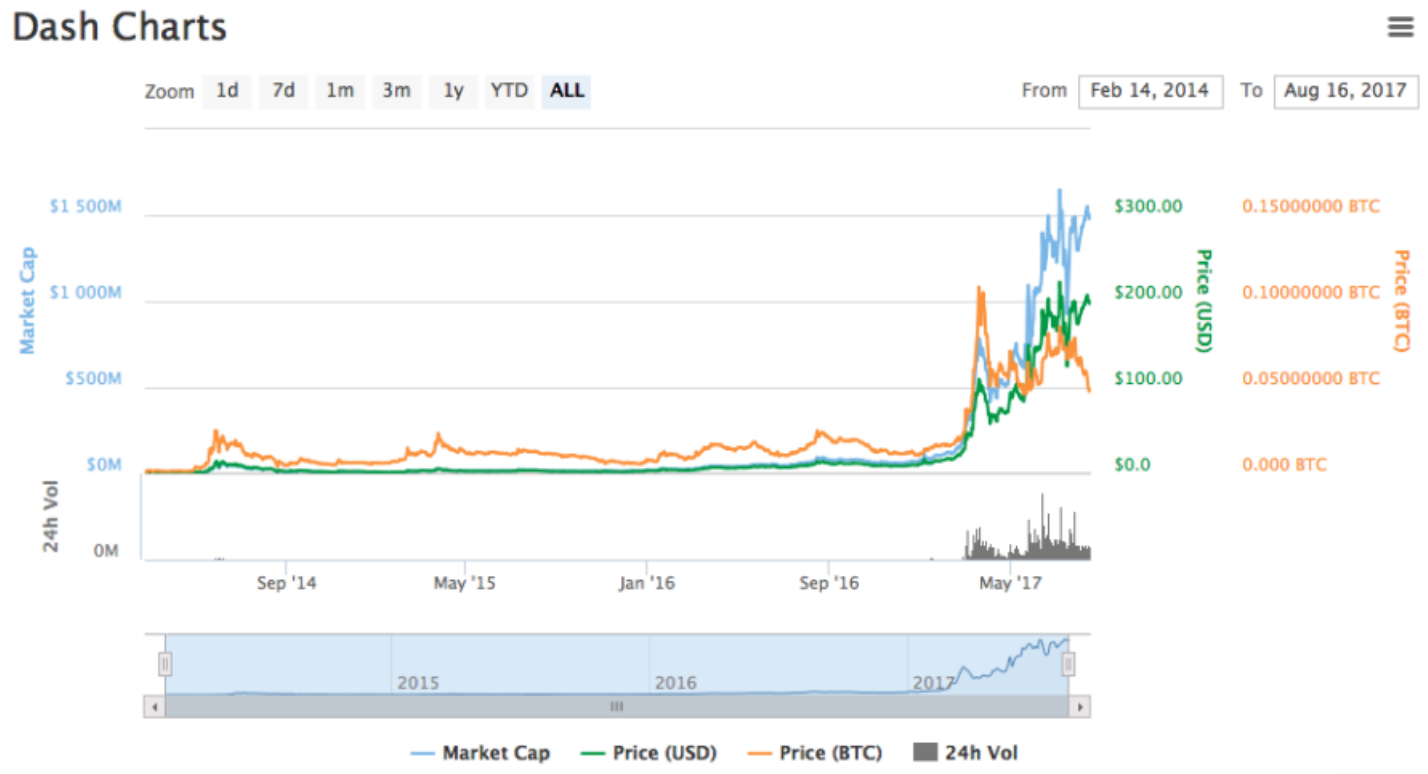


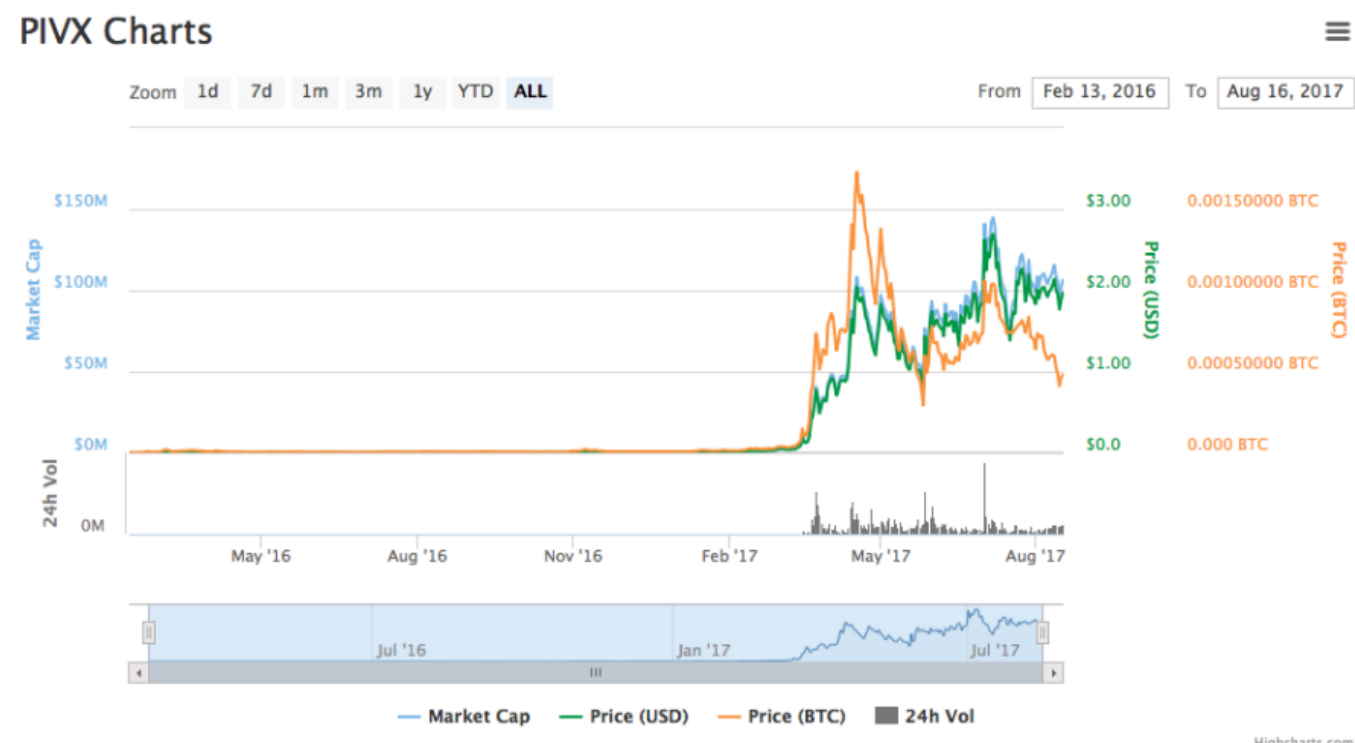

Fig 2. Year-to-date increases for Dash (previous page) and PIVX (above), retrieved from coinmarketcap.com.

\section{Background}

The funding of scientific research in the United States currently operates as an intergovernmental and private equity exercise in which monies from federal organizations, private institutions, businesses, and high net-worth individuals provide the financial capital for the production of scientific knowledge. This system functions as an often-complicated affair, involving disparate stakeholders competing for the intellectual property that research produces and researchers vying to extend their respective funding streams. Giroux noted that funding determines the kinds of research that occurs in the first place, with corporate and even military interests, for instance, privileging certain types of inquiry. ${ }^{6,7}$ Kennedy reports, for example, "By far, the dominant sources of funding for R\&D in America have been private industry and the federal government" and that "government support for development far outpaces investment in either basic or applied research ... due to the high proportion of the Department of Defense's large R\&D budget that is devoted to the development of weapons systems and other military technologies." 8 Mervis noted that the U.S. government's scientific funding peaked during the Cold War, underwriting nearly 70 percent of all science research funding. ${ }^{9}$ However, despite massive geopolitical changes, that number remained at over 60 percent as recently as 2004. Comparably, Marion Nestle noted a growing conflict between corporate concerns and science research in the field of nutrition, where private industry conducts research that might more accurately be termed marketing. ${ }^{10}$ Nestle's contentions apply to many other fields of science, including pharmaceutical research. Sergio Sismondo noted the complexities of the advancement of scientific research faces when partnering with an industry that needs to produce and sell products, ${ }^{11}$ while Piccirillo, Yueh, Davies, and Weaver recently addressed the complexities of the intersection of patient care, science funding, and corporate sponsorship. ${ }^{12}$ All of these observations speak to the ways in which the lack of diversification 
in science funding, its restriction primarily to corporate and governmental interests, erects obstacles to the sustained production of scientific knowledge.

Scientific funding for research can thus, paradoxically, hinder and even preclude novel inquiry. ${ }^{13}$ Further, the way in which resources dedicated to scientific inquiry are garnered and spent spotlights a series of complicated problems that extend beyond funding mechanisms. Ioannidis noted the dangers of a triumphalist narrative about scientific advancement in an atmosphere of already limited resources and pressure for further budget cuts, in which "vocal and aggressive competitors" receive funding over "appropriately cautious and self-critical" researchers and high-risk "innovative ideas already struggle to find support." 14 To Ioannidis's point, competition for scientific resources and knowledge is fierce, and, troublingly, scientific inquiry and funding policies are greatly influenced by policy-makers who often lack the experience or knowledge to properly make critical decisions. Haller and Gerrie noted that governmental and business interests frequently commission supposed scientific experts to support proposals and funding initiatives that are, incongruously, not vetted scientifically. ${ }^{15}$ In order to promote industry-approved perspectives, for example, the Environmental Protection Agency (EPA) recently announced that scientists receiving EPA grants are no longer eligible to serve on EPA advisory committees, and their replacements are almost certain to have strong industrial and local governmental ties.

Similarly, Greenwood and Levin discussed the increasing separation of the academic world from the governmental procedures that dictate the very policies to which academic researchers must adhere. ${ }^{16}$ Additionally, the funding system skews in favor of certain institutions, which can stifle innovation. Despite governmental efforts, funding directed toward public institutions continues to decline across all areas, but also specifically for science research-remaining substantively lower than pre-2007 levels. Mortenson has extensively examined declines in state funding, detailing yearly reductions in nearly every state since 1976, which have consequently increased the importance of competitive grant funding and existing endowments. ${ }^{17}$ The result is what Ali, Bhattacharyya, and Olejniczak noted as a pattern of social reproduction - a mechanism by which existing hierarchical social structures reproduce themselves, thereby maintaining the status quo. ${ }^{18}$ They argued that institutional resources profoundly influence the degree to which private universities are vastly outpacing public institutions in garnering NIH and NSF grants, along with other prestigious and often generous research funding. While one may argue that the distribution of such grants merely reflects the merit of these private institutions, measured in their ability to attract distinguished faculty and, via institutional endowments, to support extensive research and pass down intellectual capital, there is little doubt that a more egalitarian playing field in scientific research would yield at least a more diverse range of studies and interpretations. Further, since wealthier private institutions already possess an advantage when it comes to funding, their dominance in scientific research and its lines of inquiry becomes self-sustaining, which itself is potentially problematic.

As a counter-narrative to these processes, McKinley et al. proposed "citizen science," engaging the public in scientific projects, as a way to more fully examine scientific spending and policies. ${ }^{19}$ In proposals that are more theoretical than policy-driven, McKinley et al. presented citizen science as mitigating the dominance of scientific inquiry by industrial and other powerful external stakeholders. McKinley et al.'s conception of citizen science is a twofold process that includes collective domain knowledge building and political action. This distributed model of scientific labor and decision-making provides a useful way to think about 
disrupting the current concentration in relatively few hands of funding and resources and to reduce researchers' reliance on governmental and commercial interests.

McKinley et al.'s model, as democratic and distributive as it is, overlooked that funding for basic research is at the center of most scientific developments. Chomsky illustrated, albeit ambivalently, how governmental support for basic research has catalyzed American technological advances, new industries, and wealth-generating opportunities; ${ }^{20}$ nevertheless, his scholarship on funding did not propose any alternative. For example, Chomsky examined how Silicon Valley's startup culture revolved around government support, yet he tended to undervalue the innovation needed to wrangle that support into working technologies. ${ }^{21}$ Reif similarly recognized that funding for basic research anchors most innovations, but still supported the need to balance government funding for that research with its potential public and commercial benefits. ${ }^{22}$

One means to resist these trends is to use a cryptocurrency fund to independently generate capital for research. More specifically, institutions adopting PoS cryptocurrency funds could implement a transparent, democratic in-house mechanism to allocate generated dividends to researchers, while holding, likely for an extended time period, the original masternodes and generating more dividends. This cryptocurrency portfolio may increase funding and endowment opportunities, open avenues of research not typically favored by governmental and commercial backers, and render feasible more progressive and arguably more effective models of cooperative research.

\section{Re-Envisioning the Funding of Scientific Research}

The established process for funding scientific inquiry and its later deployment into enterprise has been remained relatively unchallenged. Ioannidis, Reif, and Chomsky made recommendations within the confines of existing policy rather than presenting alternatives to this process. ${ }^{14,22,20,21}$ Chomsky astutely framed that governmental funding propels science, yet he did not or could not propose anything other than more government funding. ${ }^{11}$ Giroux, rooting his work in Chomsky's framings, evaluated the thorniness of the American education system, and particularly scientific inquiry, which is so closely tied to military interests; ${ }^{6,7}$ yet, like all of the writers mentioned here, he failed to reimagine the current funding frameworks.

A body of literature exists, including McKinley et al. and, to a lesser degree, the work of science educators Roth and Barton, that does propose an alternative. ${ }^{19,}{ }^{23}$ However, such work may underestimate the political power of higher education institutions, government, and commercial forces to continue to appropriate the power of science. Shore described such appropriation as "neoliberal," in that it attempts to privatize public goods-in this instance, scientific research. ${ }^{24}$ With neoliberal ideology and practices firmly entrenched, there often appears to be little incentive, particularly for the well-funded scientific researcher, to challenge the current system. Lehner and Finley contended that university researchers could easily follow a careerist path, publishing in high-ranking academic journals and collecting funding from traditional sources ${ }^{25}$; yet these strategies are void of more substantial contributions to science and often undermine the student-focused mission of higher education. The result often is that current funding systems remain underexamined or that critics such as Shore and Strathern offer few practical ways to redress fundamental, systemic problems. ${ }^{24,26}$

In contrast, the proposed approach offers concrete steps to create one potential alternative path for funding scientific inquiry. Moving away from merely theorizing the dynamics of 
power within scientific funding, this work proposes that its financial tool can help to fund science without any intermediaries - in other words, without the obligations entailed by accepting National Institutes of Health, National Science Foundation, or other types of external funding. The model for this financial tool was informed by Lincoln and Guba's, Tobin's and Lehner's notion of catalytic authenticity, which notes the degree to which action was taken to create benefits for the research participants. ${ }^{27,28,29,30}$

This proposed approach also was substantially influenced by Christensen's conception of technological disruption, as well as the research methodology of bricolage. ${ }^{31}$ In recent years, bricolage has been used as a methodology by social scientists such as Denzin and Lincoln and Kincheloe, McLaren, Steinberg, and Monzó. ${ }^{32,33}$ Fundamentally, bricolage is about reassembling what is at hand into new configurations, and moving bricolage from method of inquiry into a force for scientific educational funding aligns more fully with Levi-Strauss's framing of the concept. ${ }^{34}$ By fusing catalytic authenticity with the notion of technological distribution, we refine Levi-Strauss's understanding of bricolage and purposefully deploy it as a tool for catalytic authenticity. In this proposed approach, a fresh configuration involves creating a technological disruption by combining existing cryptocurrencies and investment strategies to generate a new, alternative path to fund scientific research.

\section{Staking Coins as a Funding Source for Scientific Research}

Universities are far from the only sites of scientific research that could benefit from a cryptocurrency fund. It is possible, even desirable, that simply garnering large amounts of capital to create nonprofits or institutes could comprise the future of funding scientific research. This approach may be best exemplified by the $\$ 250$ million donation by Sean Parker for the creation of the Parker Institute for Cancer Immunotherapy (PICI). There is little doubt that consortia akin to PICI represent a forward-facing vision of science, a future that faculty/researcher-controlled cryptocurrency endowments could help to bring about. PICI does not necessarily need specific goals for continual funding (contrary to most government grants, which are entirely dependent on hundreds of predetermined criteria); the overarching ethos of the institute is that the best scientific work occurs during exploratory phases that traditional research grants simply are not engineered to support. In some cases, rigorous spending regulations even result in funds being wasted in order to remain in compliance. Additionally, Parker's initiative is unique in that rival universities' researchers collaborate and can access other researchers' aggregated data through a PICI portal. ${ }^{26}$ If this approach became more standard, scientific research might progress much more quickly and perhaps with more accuracy. The undergirding principles informing PICI, increased flexibility in spending and discretion over funds, may be replicable via a cryptocurrency fund.

The hundreds of successful initial coin offerings (ICOs) on the Ethereum network serve as a case in point for alternative funding. Ethereum, in addition to other new fundraising platforms (NEO, EOS, LISK, etc.), provides a view into new forms of fundraising. In particular, at the time of writing, NEO has surged into the seventh spot for all cryptocurrencies. NEO's recent dramatic increase in value is somewhat paradoxical, in that NEO is not fully a cryptocurrency as such. NEO, like the other coins mentioned, functions almost exclusively as a fundraising platform for other crypto projects. 


\section{Limitations and Development Hurdles}

Although staking coins are potentially lucrative, further research is required to more fully explore their viability as a long-term strategy. Admittedly, science funders must consider a variety of sometimes obscure and heterodox factors when selecting an altcoin that may yield sufficient gains. For example, NEO's ties to China could affect changes in its value. Indeed, the cryptocurrency market has seen a sharp increase in Chinese versions of existing opensource coin projects. The launch of Genaro, the Chinese version of Filecoin, is but one example, and many see NEO as the Chinese version of Ethereum. Another factor to consider is how outside actions have affected coin value growth. For example, Poloniex, one exchange where altcoins are traded, delisted 17 coins in May 2017. This action may have led to a sharp increase in a large percentage of altcoins' valuations. Such considerations present complications, however, rather than insurmountable obstacles.

Additionally, we are keenly aware of the paradox in calling for independent funding based on a prototype developed jointly with bankers. Nonetheless, the purpose of this proposed approach is more important than the allies who have helped to create the prototype. Further, the strategy of staking coins, moving away from the relatively static PoW concept, has potential for scientists and has generated substantial new capital. That said, PoS coins, specifically, can be seen as unfair to newcomers because they have the propensity to favor those with preexisting market advantages and are based on a network effect. However, the utilization of this network effect for the public good counterbalances concerns about PoS coins within the fund, as the social intelligence and reputation often required to participate are already achieved within the prototype itself; surely, leveraging a coin's potentially exclusionary characteristic for the greater good cannot be construed as harmful. As for raising capital via an ICO, we acknowledge the risk of an undervaluation without sufficient publicity but are confident that the product speaks for itself and will allow for the fund eventually to be valued by its worth alone (notwithstanding that the fund generates capital wholly independently of its coin value).

In addition to more research and prototyping, new development tools such as better coin control tools and monitoring mechanisms are required and/or need to be made publicly available on Github or another developer forum. The authors are aware of the potential for fraud but are optimistic that the type of research and reconnaissance done by the team in developing the prototype can guard against it. There are, of course, those who wonder about incoming regulations from the Securities and Exchange Commission and international governance bodies with regard to the efficacy of ICOs. The authors have consulted with and had the prototype approved by a battery of lawyers, regulators, and licensors.

\section{Conclusion}

Many intricacies encumber the process of funding scientific research within the United States. Federal organizations, private institutions, businesses, and individual donors each contribute monies in a variety of ways, making for a confusing system at best and a purposefully shrouded one at worst. Multiple interests are at play when it comes to backing scientific research of all kinds. Historically, there has not been an institutionalized opportunity to bypass this system, but the use of cryptocurrency for scientific funding can now challenge its supremacy. Cryptocurrencies and blockchain technologies offer a reprieve from the staunchly traditional endowment and grant models that depend on structures (often as limiting 
methodologically as they are insufficient financially) that have plagued scientific funding since the late nineteenth century and continue to do so well into the twenty-first. We argue that using open-source staking algorithms may be one alternative to the relatively static streams of governmental and private funding for scientific research. In particular, this proposed innovative model spotlights how a shift toward cryptocurrency for scientific funding may generate capital for scientific research and, in higher education settings, student development via dividend reinvestment. This dividend reinvestment approach not only may be both more egalitarian and accessible, but also may drive innovation by granting researchers an independence and ability to collaborate rather than compete that will benefit them, their colleagues, and the public good.

\section{Acknowledgment}

This work was greatly influenced by Kenneth G. Tobin, Presidential Professor of the Graduate Center, City University of New York. Additionally, this research was influenced by the men and women who are pioneers in the cryptocurrency space, particularly Amanda B. Johnson and Andreas Antonopoulos. We also want to thank Thomas A. Isekenegbe, President of Bronx Community College, for his support of this work.

\section{Author Contributions}

This work was jointly written by Edward Lehner, Dylan Hunzeker, and John R. Ziegler, all contributing equally.

\section{Conflict of Interest}

EL, DH, and JRZ have no affiliation with the Dash or PIVX communities.

\section{References}

${ }^{1}$ Reiss, D. "What You Should Know About Dividend Reinvestment Plans." U.S. News \& World Report (12 January 2017) https : //money . usnews . com/investing/articles/2017-01-12/what-you-should-knowabout-dividend-reinvestment-plans

${ }^{2}$ Chamber, K. "What the Big Names are Doing: Influences of Endowments \& Foundations in the Investment Philosophy." Headwater Investment Consulting (April 2015) http: //www. headwateric.com/sites/default/files/users/CBMason/topicsPapers/Topics_2015-04,Endowments.pdf

${ }^{3}$ Malkiel, B. G. A Random Walk Down Wall Street. New York: WW Norton \& Company 15-45 (1974)

${ }^{4}$ Greer, R. J. "What is an Asset Class, Anyway?" The Journal of Portfolio Management 23.2 (1997) 86-91 http://www.iijournals.com/doi/abs/10.3905/jpm.23.2.86?journalCode=jpm

${ }^{5}$ Burniske, C., White, A. "Bitcoin: Ringing the Bell for a New Asset Class." Ark Invest (January 2017) https://research.ark-invest.com/hubfs/1_Download_Files_ARK-Invest/White_Papers/BitcoinRinging-The-Bell-For-A-New-Asset-Class.pdf

${ }^{6}$ Giroux, H. A. University in Chains: Confronting the Military-Industrial-Academic Complex. Abingdon, U.K.: Routledge 52-53 (2015) 
${ }^{7}$ Giroux, H. A. "Neoliberalism's War Against Higher Education and the Role of Public Intellectuals." In M. Izak, M. Kostera, M. Zawadzki (Ed.) The Future of University Education, New York: Palgrave (2017) 185206

${ }^{8}$ Kennedy, J. V. "The Sources and Uses of US Science Funding." The New Atlantis 36 (2012)

https://www. thenewatlantis.com/publications/the-sources-and-uses-of-us-science-funding

${ }^{9}$ Mervis, J. "From the Outside Looking In." Science 329.5989 270-273 (2010)

https://doi.org/10.1126/science.329.5989.270-a

${ }^{10}$ Nestle, M. Food Politics: How the Food Industry Influences Nutrition and Health. Berkeley: University of California Press 2 (2013)

${ }^{11}$ Sismondo, S. An Introduction to Science and Technology Studies. Chichester, U.K.: John Wiley \& Sons 10-11(2011)

${ }^{12}$ Piccirillo, J. F., Yueh, B., Davies, L., Weaver, E. “Addressing the Challenges for Otolaryngology Research to Inform Patient Care and Outcomes." JAMA Otolaryngology-Head \& Neck Surgery 143.9 865868 (2017)

${ }^{13}$ Lehner, E. "The Return of the Natural Philosopher." Cultural Studies of Science Education 5.1 71-78 (2010) https://doi.org/10.1007/s11422-009-9209-2

${ }^{14}$ Ioannidis, J. P. "Defending Biomedical Science in an Era of Threatened Funding." JAMA 317.24 24832484 (2017) https : //doi.org/10.1001/jama.2017.5811

${ }^{15}$ Haller, S. F., Gerrie, J. "The Role of Science in Public Policy: Higher Reason, or Reason for Hire?" Journal of Agricultural and Environmental Ethics 20.2 139-165 (2007)

https: //doi.org/10.1007/s10806-006-9027-4

${ }^{16}$ Greenwood, D. J., Levin, M. "Reform of the Social Sciences and of Universities Through Action Research.” In N. K. Denzin, Y. S. Lincoln (Ed.) The SAGE Handbook of Qualitative Research. Thousand Oaks, CA: Sage 43-64 (2005)

${ }^{17}$ Mortenson, T. "State funding: A race to the bottom." American Council on Education (Winter 2012) http: //www. acenet. edu/the-presidency/columns-and-features/Pages/state-funding-a-race-tothe-bottom.aspx

${ }^{18}$ Ali, M. M., Bhattacharyya, P., Olejniczak, A. J. "The Effects of Scholarly Productivity and Institutional Characteristics on the Distribution of Federal Research Grants." The Journal of Higher Education 81.2 164165, 175 (2010) https://doi.org/10.1353/jhe.0.0084

${ }^{19}$ McKinley, D. C., et al. "Citizen Science Can Improve Conservation Science, Natural Resource Management, and Environmental Protection.” Biological Conservation 208 15-28 (2017) https://doi.org/10.1016/j.biocon.2016.05.015

${ }^{20}$ Chomsky N. "Public Education Under Massive Corporate Assault-What's Next?" AlterNet (August 5, 2011) https: //www.alternet.org/story/151921/chomsky\%3A_public_education_under_massive_corp orate_assault_\%E $2 \% 80 \% 94$ what 27 s_next

${ }^{21}$ Chomsky, N. "Noam Chomsky-Startup Culture.” YouTube (27 October 2015) https://youtu . be/6jhwA1vLEpU

${ }^{22}$ Reif, L. R. "How to Maintain America's Edge: Increase Funding for Basic Science." Foreign Affairs 96 95 (May/June 2017) https : / /www. foreignaffairs.com/articles/united-states/2017-03-23/howmaintain-america-s-edge

${ }^{23}$ Roth, W. M., Barton, A. C. Rethinking Scientific Literacy. Abingdon-on-Thames, U.K.: Psychology Press 2-3 (2004)

${ }^{24}$ Shore, C. "Beyond the Multiversity: Neoliberalism and the Rise of the Schizophrenic University." Social Anthropology 18.1 16-17 (2010) https://doi.org/10.1111/j.1469-8676.2009.00094.x 
${ }^{25}$ Lehner, E., Finley, K. "Should the New England Education Research Organization Start a Journal in the Age of Audit Culture? Reflections on Academic Publishing, Metrics, and the New Academy." Bronx Community College (1 August 2016) http: //academicworks.cuny .edu/bx_pubs/15

${ }^{26}$ Strathern, M. “The Tyranny of Transparency.” British Educational Research Journal 26.3 309-321 (2000) https://doi.org/10.1080/713651562

${ }^{27}$ Lincoln, Y. S., Guba, E. G. "Ethics: The Failure of Positivist Science." The Review of Higher

Education 12.3 227-228 (1989) https://doi.org/10.1353/rhe.1989.0017

${ }^{28}$ Tobin, K. "The Value to Science Education of Teachers Researching Their Own Praxis." Research in Science Education 29.2167 (1999)

${ }^{29}$ Tobin, K. G. "Sociocultural Perspectives on Science Education.” In B. J. Fraser, K. G. Tobin, C. J. McRobbie (Ed.) Second International Handbook of Science Education. New York: Springer 4-7 (2012)

${ }^{30}$ Lehner, E. "Describing Students of the African Diaspora: Understanding Micro and Meso Level Science Learning as Gateways to Standards Based Discourse.” Cultural Studies of Science Education 2.2449 (2007)

${ }^{31}$ Christensen, C. M. The Innovator's Dilemma: When New Technologies Cause Great Firms to Fail. Brighton: Harvard Business Review Press 3-35 (2013)

${ }^{32}$ Denzin, N. K., Lincoln, Y. S. "Introduction: The Discipline and Practice of Qualitative Research.” In N. K. Denszin, Y. S. Lincoln (Ed.) The SAGE Handbook of Qualitative Research (5th ed.). Thousand Oaks, CA: Sage 11-14 (2017)

${ }^{33}$ Kincheloe, J. L., McLaren, P., Steinberg, S. R., Monzó, L. D. “Critical Pedagogy and Qualitative Research: Advancing the Bricolage.” In N. K. Denszin, Y. S. Lincoln (Ed.) The SAGE Handbook of Qualitative Research (5th ed.) Thousand Oaks: Sage 235-260 (2017)

${ }^{34}$ Levi-Strauss, C. The Savage Mind. London: Weidenfeld and Nicolson 16-22 (1966)

35 “Our Model." Parker Institute for Cancer Immunotherapy (accessed 18 August 2017) https://www.parkerici.org/our-model/

(cc) BY ULLS
Articles in this journal are licensed under a Creative Commons Attribution 4.0 License.

Ledger is published by the University Library System of the University of Pittsburgh as part of its D-Scribe Digital Publishing Program and is cosponsored by the University of Pittsburgh Press. 